\title{
ESCOLAS OCUPADAS NO RIO DE JANEIRO EM 2016: MOTIVAÇÕES E COTIDIANO
}

\author{
Diógenes Pinheiro'
}

Este relato resulta da experiência de um projeto de extensão da Universidade Federal do Estado do Rio de Janeiro (UNIRIO), que acompanhou algumas ocupações em escolas de ensino médio em 2016, e ouviu tanto estudantes que participavam quanto outros que não participavam desse movimento social. O objetivo foi entender as motivações e seguir as atividades no cotidiano das ocupações, dialogando com pesquisas sobre ativismo juvenil no recente ciclo de políticas públicas de juventude no Brasil. Interessa refletir sobre as questões colocadas por essas novas formas de participação política, pois tocam em temas centrais sobre o sentido da educação para os jovens de hoje. Afinal, a pergunta que as ocupações colocavam era: qual é a escola que queremos? Isso implicava refletir sobre os dilemas da escola que tinham.

A partir de 2015, as ocupações de escolas foram se transformando em um movimento social nacional da juventude secundarista brasileira, que respondia simultaneamente a questões nacionais e locais. No Rio de Janeiro, as ocupações ocorreram em maio e outubro de 2016. Em maio, o movimento se iniciou em apoio à greve docente e impulsionado pelas críticas aos gastos dos governos estadual e municipal com os chamados megaeventos (Copa do Mundo de Futebol, 2014; Olimpíadas, 2016).

À medida que a conjuntura política entrava na escola, a pauta de reivindicações foi se ampliando. Em outubro, as ocupações tinham como pano de fundo o congelamento das despesas governamentais com educação. Contrastando com a precária infraestrutura das escolas, tais medidas eram vistas pelos jovens ativistas como um descaso com a qualidade da Educação, principal reivindicação da juventude organizada desde a $2^{\text {a }}$ Conferência Nacional de Juventude, realizada em 2011. Mas a esse combustível político da conjuntura, se somaram questões internas, desde direções de escola autoritárias, geralmente não eleitas pela comunidade escolar e que impunham restrições à organização dos estudantes em grêmios, até as péssimas condições das instalações escolares.

\footnotetext{
${ }^{1}$ Universidade Federal do Estado do Rio de Janeiro, Brasil.
} 
Assim, a crise política vivida no país se transformou numa perspectiva para os estudantes observarem com mais clareza as precárias condições da infraestrutura e o peso da hierarquia escolar. Nesse contexto, essas questões vivenciadas no cotidiano escolar geraram um crescente sentimento de injustiça (Barrigton Moore Jr., 1987), que ultrapassou os limites do aceitável. A rápida expansão do movimento de ocupação representava esse acúmulo de força e indignação dos coletivos juvenis em processo de constituição, que - justamente por estarem em formação - tinham mais flexibilidade para experimentar novas estratégias de ação política.

Sitrin (2012) alerta que há uma mudança importante no sentido dos movimentos de ocupação em relação a movimentos sociais clássicos, pois seu objetivo não é propor soluções para os problemas enfrentados, mas, sim, abrir um diálogo amplo com todos os envolvidos. Por isso, as ocupações diferem da maioria dos movimentos sociais, cujas ações consistem na demonstração pública de sua força, através de passeatas com seus desfiles de bandeiras e palavras de ordem, visando reafirmar seu poder de pressão para o encaminhamento de demandas. As ocupações, ao contrário, se fecham para o público em geral e buscam abraçar simbolicamente aquele espaço que acreditam estar ameaçado, repensando seus sentidos.

\section{O início do projeto de extensão}

Este projeto de extensão surgiu a partir de uma reivindicação de estudantes de graduação em Pedagogia, da disciplina Educação Popular e Movimentos Sociais, que queriam acompanhar de perto as ocupações das escolas que cresciam rapidamente em maio de 2016, às vésperas dos Jogos Olímpicos que seriam sediados na cidade do Rio de Janeiro. Esses estudantes universitários eram, eles próprios, jovens e/ou recém-saídos do ensino médio, e olhavam com admiração - e, diria, com uma ponta de inveja - as mobilizações que os secundaristas promoviam em torno de temas que eles também experimentavam na universidade, como a precariedade da infraestrutura. Como seria uma atividade realizada fora da universidade, a melhor alternativa foi formular um projeto de extensão universitária, que consistia em visitas às escolas ocupadas, não só como forma de solidariedade, mas também para a abrir um diálogo entre jovens secundaristas e universitários sobre o sentido da educação. Portanto, o objetivo era colaborar em atividades e ofertar oficinas sobre temáticas variadas. Foi elaborado, 
também, um breve questionário, no googledocs, que pudessem aplicar usando seus telefones celulares.

Em maio de 2016 visitamos sete escolas ocupadas no município do Rio de Janeiro. Inicialmente, os universitários entraram em contato com representantes das ocupações, através das páginas da escola ocupada no facebook, buscando os coletivos que tivessem interesse em conversar. Em seguida, a turma se dividiu em grupos que visitaram essas escolas nas duas semanas seguintes, no horário da disciplina cursada na universidade. Nessa etapa, foi possível conversar com 47 jovens, todos participantes das ocupações. A visita se iniciava com uma roda de conversa, onde ouvíamos os relatos de como se deu o processo de ocupação e quais suas principais motivações. Em seguida, aplicava-se o questionário com 12 questões, percorrendo informações básicas sobre o estudante (idade/série), problemas da escola, motivações para a ocupação, redes de apoio (familiares/movimentos sociais/partidos).

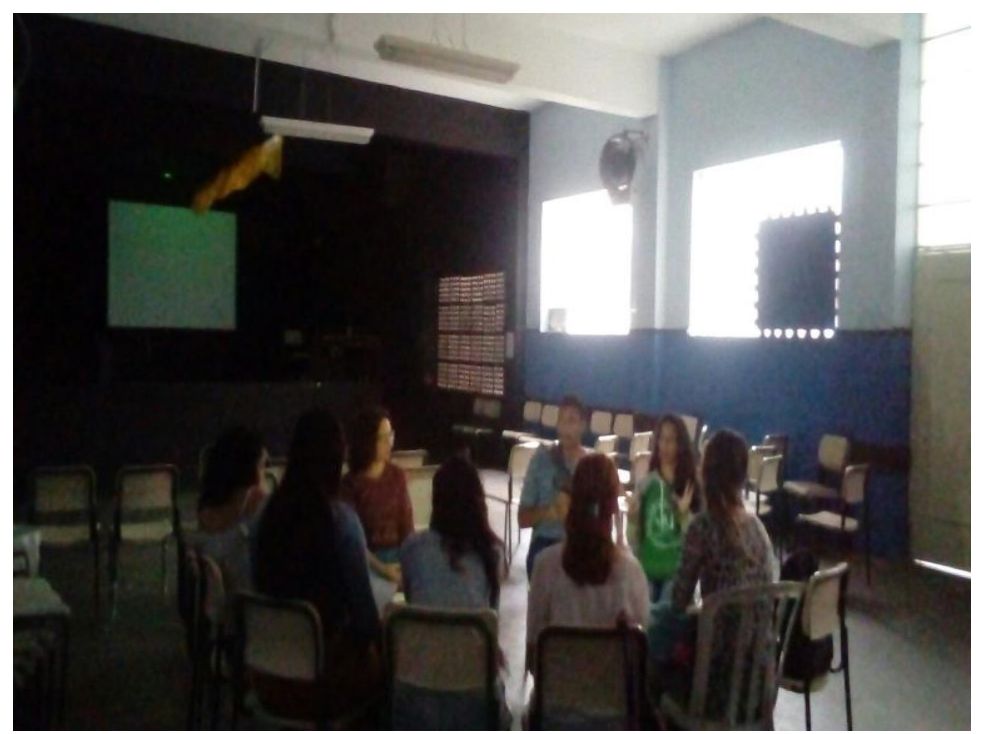

Roda de conversa em escola ocupada, RJ, 2016. Foto: D. Pinheiro.

Devido às inovações que os jovens estavam produzindo nas ocupações misturando desde ferramentas clássicas da Educação Popular até o web ativismo, presente na conexão e troca de informações em tempo real entre as escolas ocupadas tornava-se fundamental incorporá-los como sujeitos ativos na compreensão da dimensão político pedagógica das ocupações. Por isso, as reflexões metodológicas da Extensão Universitária foram muito úteis para o desenvolvimento dessa pesquisa, pois serviram 
para destacar o caráter dialógico da produção do conhecimento, onde a troca de saberes e experiências é o princípio filosófico da prática, apoiada na interação e no cotidiano compartilhado ${ }^{2}$.

Oliveira (1998) ensina uma lição para os Antropólogos, mas que vale para qualquer pesquisador que se utilize do trabalho de campo como ferramenta de apreensão do real: a necessidade de problematizar, permanentemente, os dados coletados. Lidar com o distanciamento e a proximidade é, na pesquisa social, um exercício constante, mas, nem por isso, fácil de ser realizado, sobretudo quando se dá em situações limítrofes, como as experimentadas por movimentos sociais, pois não se sabe, efetivamente, os desdobramentos da ação. Por isso, diz ele, é preciso aprender a construir uma forma de olhar, ouvir e escrever. Geralmente, as Ciências Sociais buscam no distanciamento uma forma de objetivar suas observações do real. Porém, na experiência das ocupações, foi mais importante buscar a proximidade e seguir de perto o olhar dos estudantes secundaristas, pois eles nos mostravam uma outra escola, diferente das representações e experiências que nós, universitários, tínhamos da escola que frequentamos no passado.

Talvez esse encontro tenha sido tão intenso em função do momento político vivido pelo país em 2016, quando um golpe parlamentar, jurídico e midiático retirava direitos e buscava retroceder em conquistas de um ciclo de expansão de políticas de juventude que, entre 2005 e 2015, promoveu avanços, principalmente no que diz respeito ao direito à educação. Por isso, havia um espírito de trincheira nas ocupações, acentuado pelo temor da invasão da polícia, pela restrição de quem entrava e saía, pela entrega de alimentos, pela cozinha comunitária e pelos dormitórios improvisados em salas de aula. Tudo isso trazia uma aura mágica às ocupações, o que acabou por ressaltar os sentidos subjetivos da experiência. Isso levou à necessidade de um registro das imagens das ocupações, pois eram muito fortes, eram denúncia e reflexão. Em alguns momentos, esses retratos da escola valiam mais do que mil palavras.

\footnotetext{
${ }^{2}$ Para informações sobre a Política Nacional de Extensão Universitária, bem como para acesso aos documentos metodológicos que regem o trabalho extensionista, ver a página da Rede Nacional de Extensão (RENEX), disponível: https://www.ufmg.br/proex/renex/index.php/apresentacao/documentos
} 


\section{A conjuntura política entrou na escola}

Em maio de 2016, o Rio de Janeiro experimentava um clima bastante politizado, especialmente entre a juventude, desde os setores mais organizados até os novos coletivos juvenis, que vinham pautando as lutas pelo direito à cidade desde 2013. Naquele momento, o pano de fundo eram os gastos excessivos dos governos municipal e estadual com as obras da Copa do Mundo de 2014 e das Olimpíadas de 2016, mas em março teve início uma greve dos professores da rede estadual, no que viria a se tornar o maior movimento de paralização da categoria.

Havia, também, uma forte influência da conjuntura nacional. Em 13 de maio, o processo de impeachment da presidenta Dilma Rousseff, iniciado em dezembro de 2015, colocou o vice-presidente Michel Temer interinamente na Presidência da República, dando início às manifestações de rua que marcam esse momento de ruptura institucional no país. A conjuntura política invadiu a escola. A consumação do golpe foi a gota d'água que faltava para entornar o pote das insatisfações estudantis. Parecia que os descalabros financeiros e políticos rebatiam e ecoavam na péssima infraestrutura das escolas ocupadas, que expunham em suas fachadas os motivos deste gesto tão dramático.



Fachada de escola ocupada, RJ, 2016. Foto: D. Pinheiro. 
O gatilho que disparou o movimento de ocupação foi a solidariedade à greve docente, manifestando a vontade dos estudantes secundaristas de se engajarem na luta em prol da melhoria da escola pública. Em meio a uma sociedade que parecia assistir bestializada ${ }^{3}$ a usurpação de seus direitos, a bravura de ativistas tão jovens gerou uma onda de solidariedade em relação às privações que os estudantes estavam passando para defender, literalmente, o seu direito à educação. Com isso, criou-se uma razoável rede de apoio às ocupações, que envolvia desde familiares dos estudantes, pessoas da vizinhança até artistas e blogueiros. Assim, as escolas eram abastecidas de comida e água, além de receberem convidados diversos que iam dar aulas públicas, assistência jurídica ou apoio moral. Foi muito comum a presença de ex-alunos que ao saberem da ocupação voltaram as suas antigas escolas para realizar atividades com os ocupantes.

\section{O cotidiano das ocupações}

O que caracterizava o cotidiano das ocupações era um conjunto de atividades muito organizadas do ponto de vista político pedagógico, visando responder à pergunta inicial sobre os sentidos da escola. Essas atividades iam desde oficinas de fotografia, grafite até rodas de discussão sobre a conjuntura política. Imediatamente após a ocupação da escola, era realizada uma faxina geral nos espaços abandonados ou degradados. Camadas de descaso do poder público e de más gestões escolares foram sendo expostas. Quase todas as intervenções buscavam criar espaços de convivência, onde os estudantes pudessem, simplesmente, sentar e conversar. Eles descreviam a ocupação usual do espaço escolar como sendo opressiva, pois tinham que circular em linhas pré-determinadas: do pátio para as salas e dessas para o refeitório ou para a quadra de esportes. Sentiam falta desses espaços para interação, onde pudessem fruir o tempo na escola.

\footnotetext{
${ }^{3}$ Expressão utilizada por Carvalho (1987) para descrever o comportamento apático da maioria da população assistindo o acordo entre as elites que culminou com a Proclamação da República, em 1889.
} 


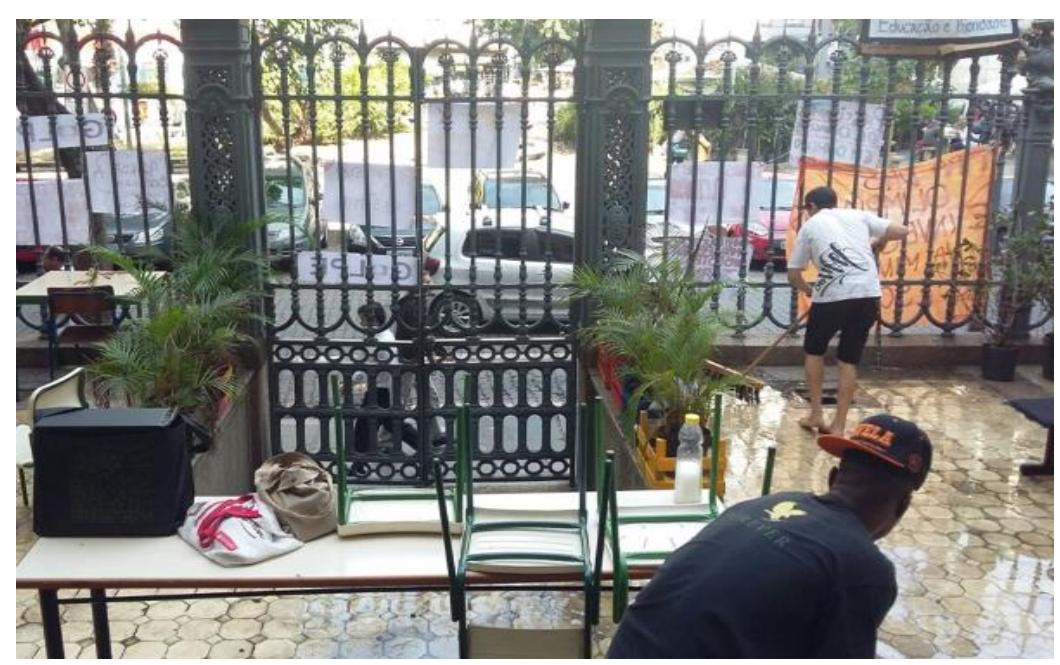

Faxina em escola ocupada, RJ, 2016. Foto: D. Pinheiro.

Havia uma divisão de tarefas que envolvia todos os estudantes, indo desde atividades internas rotineiras, como limpeza e cozinha, até a manutenção da rede de contatos e apoios entre as escolas, bem como com representantes da sociedade civil que estavam dando apoio, principalmente alguns parlamentares fluminenses. Em função do clima tenso que marcava a rotina das ocupações, sobretudo à noite, havia uma grande preocupação com a segurança, pois os estudantes eram ameados, de um lado, pela polícia e, de outro, por grupos jovens de direita, que atacavam as escolas com pedras e ameaçaram os estudantes ocupantes. Tais conflitos ocorreram em várias ocupações. $\mathrm{O}$ temor de uma invasão violenta gerava preocupação porque muitos dos ataques ocorridos vandalizaram instalações, visando, assim, acusar o movimento de ocupação de ter depredado o patrimônio público. Por isso, havia um zelo grande em manter os espaços permanentemente arrumados e, além disso, tudo era filmado e enviado em tempo real para outras ocupações, como forma de se resguardarem de futuras acusações inverídicas. 


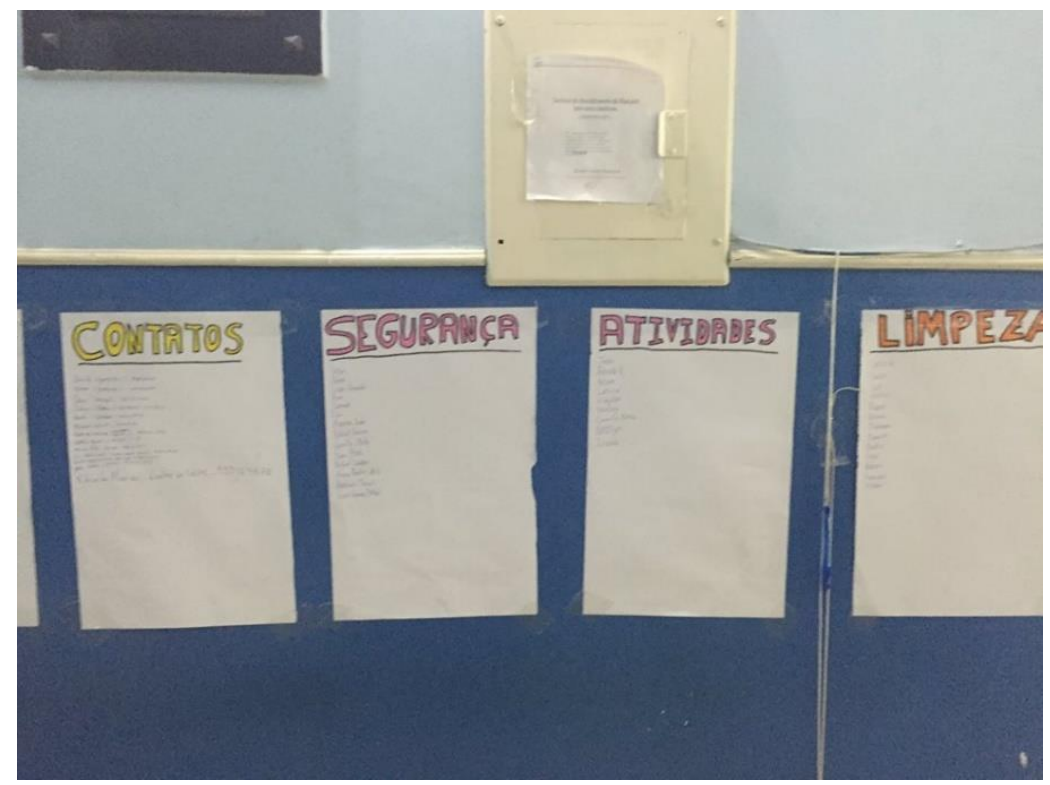

Quadro de divisão de tarefas em escola ocupada, RJ, 2016. Foto: D. Pinheiro.

Os grafites foram a marca registrada de todas as ocupações. Seus murais continham sínteses da visão dos jovens sobre política que evocavam de forma ágil e provocativa as contradições que viam no mundo político. Como em quase todas as escolas, a grande presença feminina entre os ocupantes trouxe com muita força as discussões de gênero.



Grafite em escola ocupada, RJ, 2016. Foto: D. Pinheiro. 
Ao contrário do que afirmava o senso comum mais conservador, os estudantes que ocuparam as escolas valorizavam muito as aulas e foi bastante comum a presença de professores da própria escola, principalmente os de Filosofia e Sociologia, e de convidados externos, ministrando os chamados "aulões", isto é, aulas coletivas que tratavam de temas contemporâneos, geralmente de interesse dos jovens ativistas.

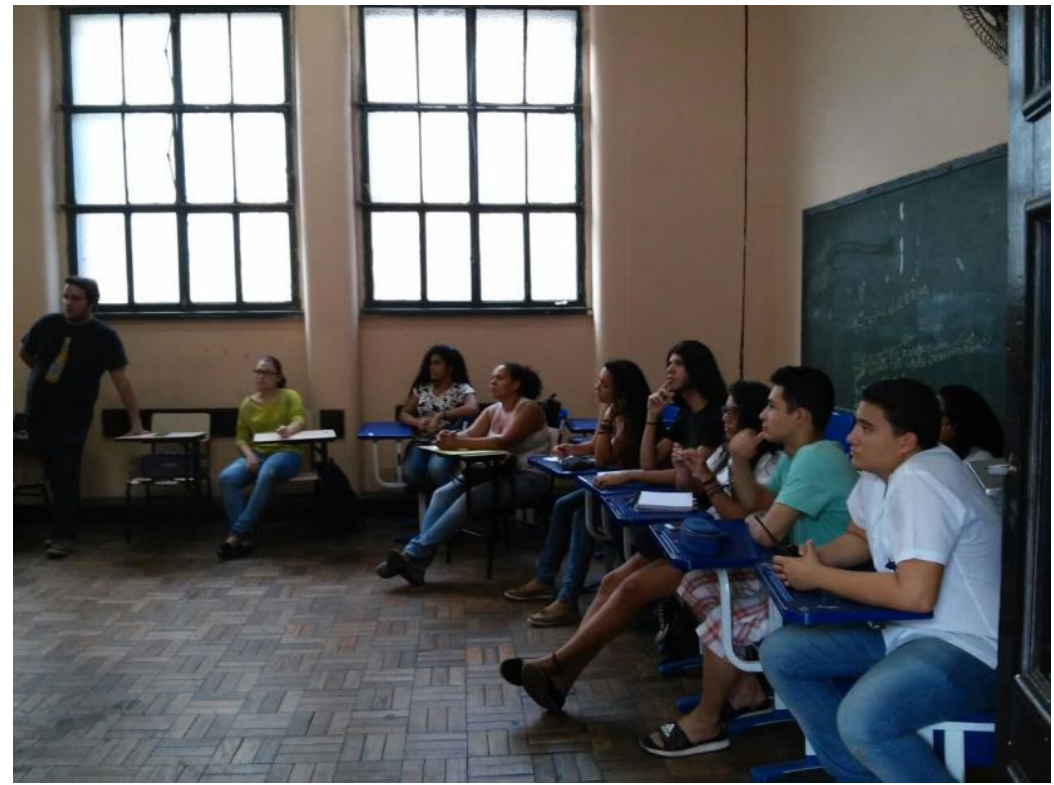

“Aulão” em escola ocupada, RJ, 2016. Foto: D. Pinheiro.

\section{Motivações para as novas ocupações}

Em outubro de 2016, a segunda etapa da pesquisa foi realizada junto com a turma de graduação em Ciências Sociais, que cursava a disciplina Metodologias Quantitativas em Ciências Sociais. Naquela ocasião, foi reformulado o questionário para captar, também, as percepções de estudantes que não participavam das ocupações, além de ampliar o tamanho da amostra, abrangendo movimentos que ocorriam em outros municípios, além do Rio de Janeiro, como Duque de Caxias, Japeri, Nova Iguaçu e Queimados, uma vez que a segunda onda de ocupações tocava em questões mais amplas, tendo como pano de fundo o Projeto de Emenda Constitucional (PEC) que congelava, por 20 anos, os gastos públicos, entre eles os com a Educação. Nessa fase, responderam ao questionário 75 estudantes, a maioria (52) não participava das ocupações. 
Na sua percepção, qual a principal motivação para a ocupação das escolas?

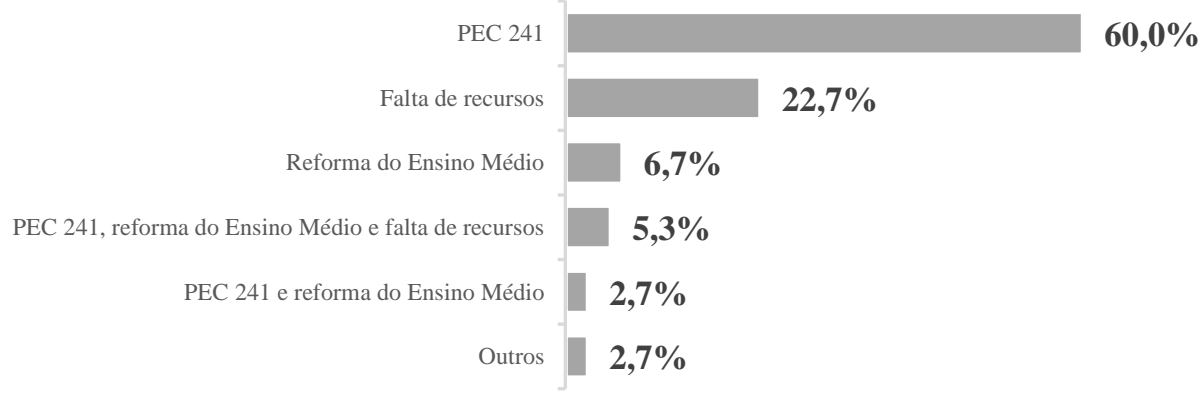

Total de respostas: 75

Olhando a conjuntura nacional, o corte de verbas para a Educação impactava diretamente a sua principal demanda da juventude: melhorias na qualidade da Educação, a começar pelas instalações físicas, que lhes pareciam demasiadamente precárias.

Em geral, na sua percepção, qual seria o principal problema da sua escola?

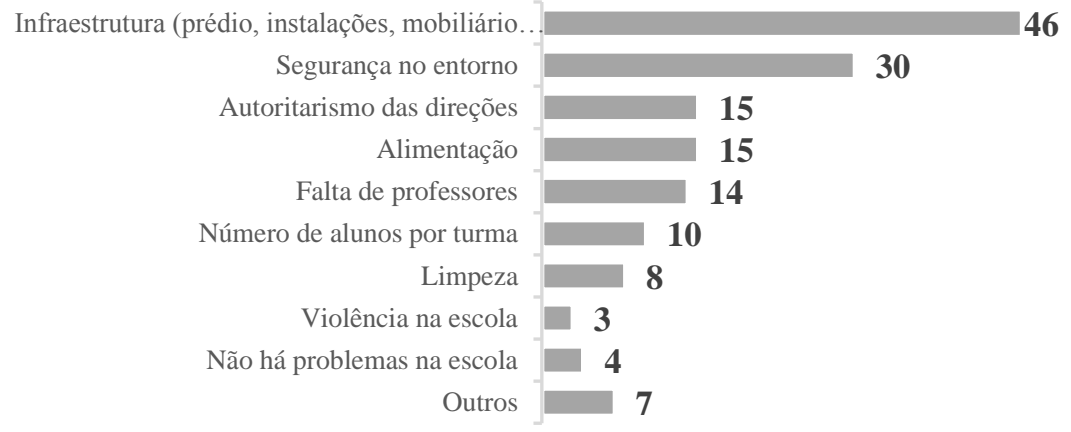

Total de respostas: 75

As respostas a essa questão trouxeram à tona, pela primeira vez, um tema que se tornaria o grande incômodo dessa experiência: o papel nefasto de direções de escola autoritárias, cujas ações iam em direção contrária ao que prega a lei e ao que recomendam as teorias pedagógicas contemporâneas. Conforme as ocupações foram se desenvolvendo, mais e mais casos semelhantes de má gestão e autoritarismo foram sendo divulgados, envolvendo desde o racionamento na oferta de alimentação aos estudantes até laboratórios de informática permanentemente trancados - isso para a 
primeira geração jovem nascida em um mundo inteiramente digital! - além de muitos livros didáticos não distribuídos.

Em todas as escolas visitadas, os estudantes fizeram uma visita guiada para mostrar as atividades que estavam acontecendo, como "aulóes", rodas de conversa, faxina em espaços deteriorados, cozinha e dormitórios improvisados. Segundo os estudantes, esses registros fotográficos estavam sendo enviados para a Secretaria Estadual de Educação com a solicitação de abertura de processos administrativos contra alguns diretores de escola.

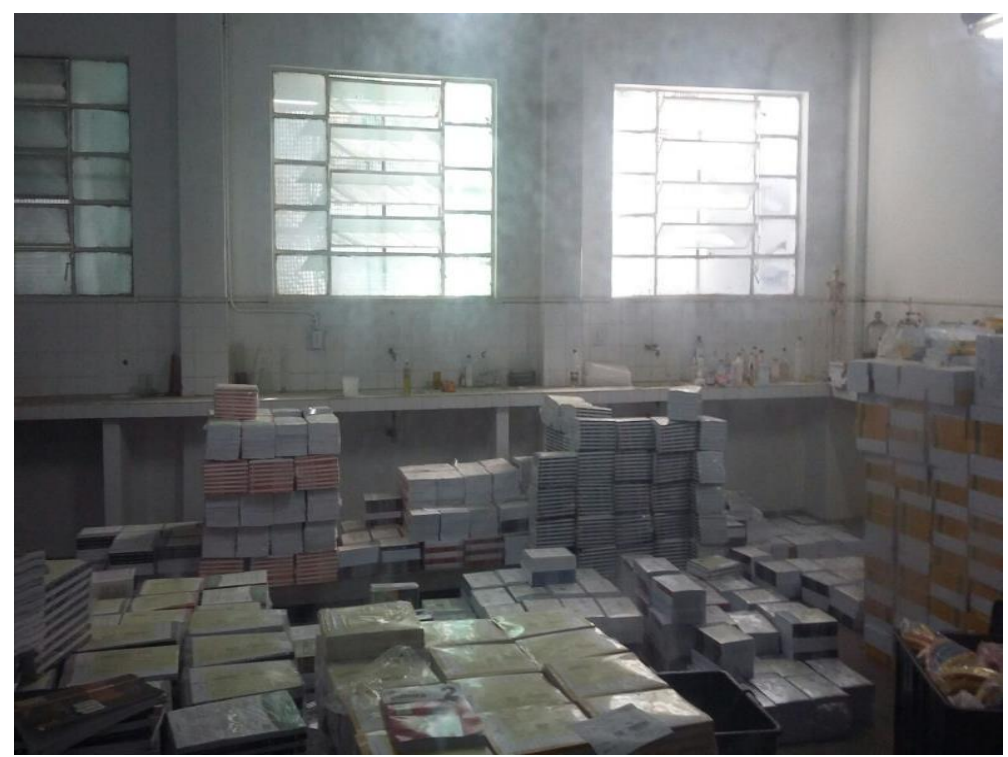

Material didático não distribuído em escola ocupada, RJ, 2016. Foto: D. Pinheiro. 
Em um trabalho quase arqueológico, espaços ocultos dentro da escola foram sendo descobertos, principalmente laboratórios de informática.

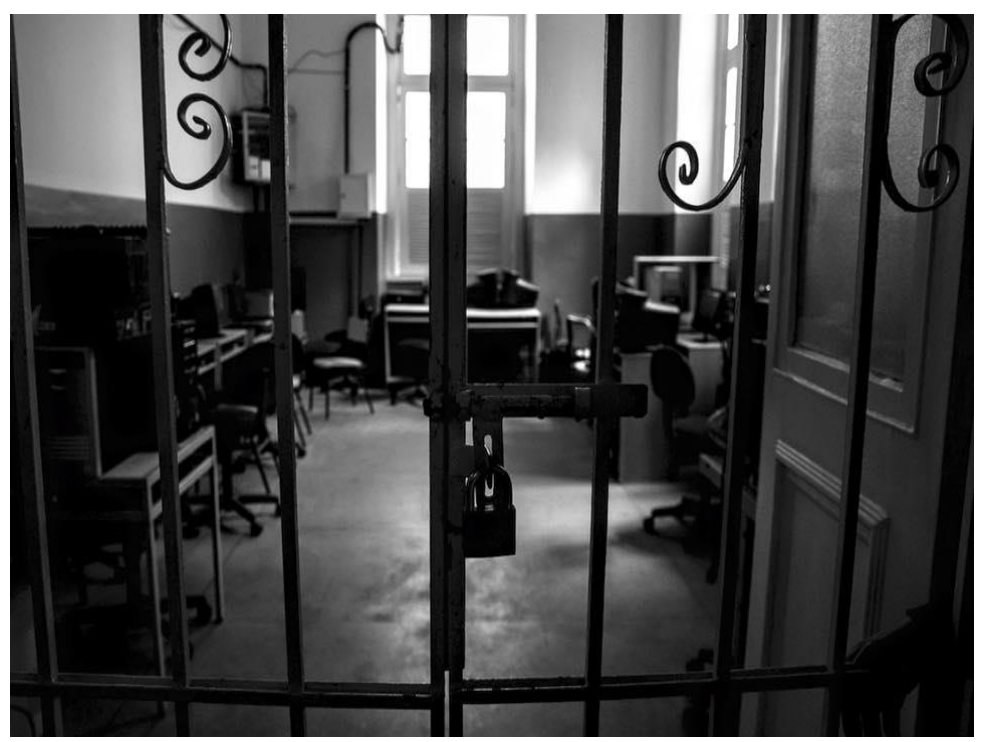

Laboratório de informática trancado em escola ocupada, RJ, 2016. Foto: D. Pinheiro.

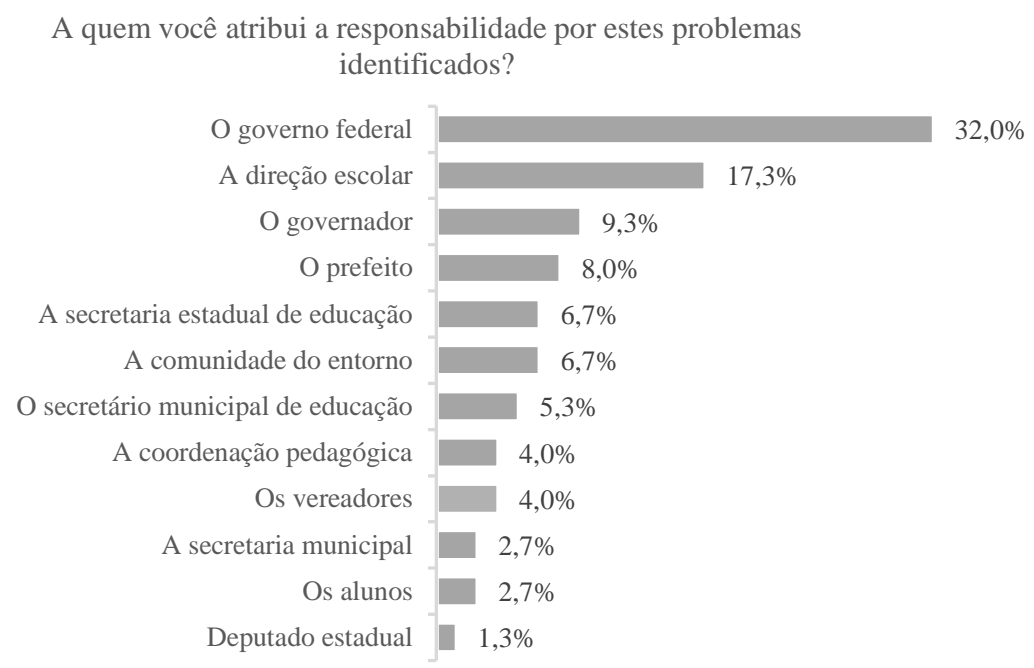

Total de respostas: 75

Embora esteja inscrita no âmbito dos princípios que regem a educação nacional, tanto na Constituição Federal de 1988 quanto na LDB, 1996, a gestão democrática ainda é um daqueles direitos consagrados, porém não praticados. Quando muito, envolve a participação do corpo docente nas decisões da direção escolar, mas raramente 
contempla a participação de estudantes. No que tange às decisões sobre o uso do espaço escolar, havia uma grande insatisfação entre os estudantes entrevistados, pois as direções, certamente pressionadas pela Secretaria Estadual de Educação, priorizavam a construção de mais salas de aula, utilizando, para tal, espaços comuns, como quadras de esporte ou teatros. Longe de querer culpabilizar unicamente as direções pelas péssimas condições de muitas escolas públicas, não se pode desconhecer a existência de tais problemas, o que demonstra, de um lado, a necessidade de se assegurar a observância da lei e, de outro lado, a urgência de se empreender um esforço mais sistemático de oferta de cursos de formação em gestão escolar.

\section{Ativismo juvenil no Brasil contemporâneo}

$\mathrm{Na}$ tradição do pensamento social, o ativismo político tem como antítese a alienação (Elias, 1998). Por alienação, se entende a separação do homem das condições que o habilitam para o exercício pleno da liberdade. Assim, alienação significa não conseguir se reconhecer como produtor de valor no trabalho, na cultura e, principalmente, na política. Por isso, alienação significa a privação voluntária da vontade de agir no mundo, mesmo que a renúncia à participação não seja completamente consciente e, portanto, percebida como um déficit de cidadania. Nas democracias modernas, certos grupos possuem vantagens no processo de representação em relação a outros, tornando desigual a capacidade de acesso a serviços ou a garantias de direitos, devido à maior capacidade de pressão que alguns atores têm sobre as instâncias do poder que estão diretamente envolvidas nas tomadas de decisões. Porém, a lógica democrática afirma que o avanço das práticas de representação política leva ao aperfeiçoamento do sistema representativo, o que pode ser visto, historicamente, através da crescente incorporação de demandas, direitos e sujeitos que anteriormente não eram reconhecidos na agenda política.

No caso brasileiro, uma mudança importante deve ser destacada quando se pensa o ativismo político juvenil, que foi a recente transformação na forma como o Estado trata as demandas da juventude, iniciada com a implantação de uma Política Nacional de Juventude, em 2005, consubstanciada na criação de três espaços institucionais em nível federal - a Secretaria Nacional de Juventude (SNJ), o Conselho Nacional de Juventude (Conjuve) e o Programa Nacional de Inclusão de Jovens: Educação, 
Qualificação e Ação Comunitária (ProJovem) -, vinculados diretamente à Secretaria da Presidência da República. A existência de um arcabouço institucional permitiu a incorporação progressiva de novos grupos e expressões juvenis, que foram se afirmando como sujeitos de direitos.

Assim, em suas lutas por reconhecimento, a juventude diversificou a pauta de reivindicações e afirmou novas identidades políticas, como os jovens negros, quilombolas, de terreiro, assentados, GLBT (gays, lésbicas, bissexuais e transgêneros), convivendo com os movimentos já veteranos na cena política, como o movimento estudantil tanto universitário quanto secundarista, grupos religiosos, jovens de partidos políticos, da capoeira, do funk e do hip hop. ${ }^{4}$ Este diálogo a partir da diversidade é um dado novo no cenário no qual se inserem as reivindicações políticas da juventude. Diversidade que talvez nenhuma geração precedente tenha experimentando tão intensamente. Como ponto em comum, está o fato de o Estado ser o interlocutor primordial para o qual essa rede juvenil se volta em busca de recursos e de marcos legais de regulação.

Em dezembro de 2011, foi realizada a $2^{\text {a }}$ Conferência Nacional de Políticas Públicas de Juventude (CNPPJ), que teve como lema "Juventude, Desenvolvimento e Efetivação de Direitos". No processo de mobilização, foram eleitos 1400 jovens delegados, representando diferentes coletivos (partidos políticos, grupos religiosos, GLBTs, de terreiros, movimento negro, assentados e ribeirinhos etc.), que trouxeram demandas, um mapeamento e uma reflexão inicial sobre os principais problemas que enfrentam em seus estados, cidades, bairros e comunidades de origem. Ao serem convidados a apontar os três principais problemas do Brasil na atualidade, num rol de 21 opções, a qualidade da Educação foi a mais frequente, configurando-se na maior das preocupações para os jovens pesquisados. ${ }^{5}$

\footnotetext{
${ }^{4}$ Sobre o tema, ver Novaes, 2006.

${ }^{5}$ Pinheiro, Esteves e Farah Neto (2014), analisando respostas a um questionário aplicado a 1209 participantes da $2^{\mathrm{a}} \mathrm{CNPPJ}$, em sua maioria (82\%) jovens delegados eleitos, afirmam ser a qualidade da Educação o problema mais grave do Brasil para $46 \%$ dos entrevistados e a principal questão para a juventude brasileira, na opinião de $51,4 \%$ dos respondentes. Curiosamente, a escola aparece em $5^{\circ}$ lugar, entre as instituições que mais confiam, perdendo inclusive para as igrejas, que ocupam a $4^{\mathrm{a}}$ posição e para a família ( $1^{\circ}$ lugar), movimentos sociais ( $2^{\circ}$ lugar). Movimentos juvenis ( $3^{\circ}$ lugar).
} 
Em 2013, as chamadas Jornadas de Junho da juventude surgiram de maneira inesperada e demonstraram um grau de insatisfação dos jovens em relação à política que as pesquisas, até então, não haviam detectado como algo que estivesse latente. Essa lacuna nas análises se devia, em parte, à maior institucionalidade alcançada pela temática da juventude no governo federal, que deslocou o foco das pesquisas para aquela parcela de jovens com maior ativismo político. Talvez isso tenha nublado a visão em relação à maior parte da juventude, que não participava de nenhuma rede ou movimento social, nem era assistida por nenhum programa social. Nas escolas ocupadas visitadas neste projeto, o perfil majoritário era de jovens sem experiência prévia de militância e as referências às Jornadas de Junho estiveram presentes em todas as entrevistas feitas. Em 2013, eles tinham entre 14 e 15 anos e mesmo os que não foram às ruas relembram aquele momento como o seu despertar para a política.

Em agosto de 2013, como primeiro resultado desse intenso processo de mobilização, foi aprovado o Estatuto da Juventude (Lei n ${ }^{\circ} 12.852$, de 05 de agosto de 2013), que é hoje o instrumento legal que define os direitos que devem ser garantidos e promovidos pelo Estado brasileiro aos cerca de 52 milhões de jovens entre 15 a 29 anos. Afirma-se legalmente o paradigma do jovem como sujeito de direitos, que deixa de ser visto como objeto de tutela ou beneficiário das ações do Estado e passa a ser considerado como ator relevante na formulação e implementação das políticas no campo da juventude. Porém, avançar da afirmação deste princípio democrático ao ato efetivo de participação da juventude, em todas as etapas das políticas em curso, constitui, ainda, um desafio.

A $3^{\text {a }}$ Conferência Nacional de Juventude foi realizada em dezembro de 2015, com o processo de ruptura política já em curso, e teve como lema "As várias formas de mudar o Brasil", que sintetizava as experiências acumuladas na última década em termos de projetos e políticas inovadoras de juventude.

Cabe perguntar: quais os impactos de uma maior politização da juventude sobre a dinâmica das relações dos jovens com a escola? Como afirma Freitas (2016), na percepção dos jovens, a escola está atenta às questões contemporâneas, mas pouco conectada ao território onde está inserida e, com isso, querem dizer que a escola entende os jovens, mas não está muito preocupada com seus problemas. Segundo a autora, a relação dos jovens com a escola é marcada, cada vez mais, por aproximações, mas, também, por afastamentos: 
No entanto, considerando que entender seus alunos e dialogar com suas questões é condição sine qua non para que a escola possa realizar um processo educativo satisfatório, é preocupante que apenas um quarto dos jovens avalie como plenamente satisfatória em ambos os aspectos, e que as maiores parcelas a avaliem apenas como razoavelmente satisfatória (Freitas, 2016: 141).

Sem dúvida, a escola precisa repensar sua relação com os estudantes, principalmente no que diz respeito à necessidade que eles têm de participar ativamente nas decisões que lhes dizem respeito. O maior desafio é a expansão da pauta para questões mais cotidianas da escola, como a ocupação dos espaços e as relações hierárquicas.

\section{Considerações finais}

As ocupações cariocas surpreenderam mais pela rapidez com que se espalharam e pela qualidade dos debates travados no processo de experimentação de um formato organizativo novo para o próprio movimento juvenil. E representaram, também, uma primeira reação às investidas de grupos neofacistas que buscam um maior controle sobre a Educação, como o Escola Sem Partido (ESP) e o Movimento Brasil Livre (MBL). As práticas pedagógicas e políticas desenvolvidas nas ocupações demonstravam a necessidade de reflexão coletiva sobre a escola. O que esses estudantes questionavam era a experiência pobre que lhes era oferecida cotidianamente. Para tanto, era preciso suspender a normalidade da rotina escolar - suas grades curriculares, tempos e espaços pré-definidos - virar esse cotidiano de ponta-cabeça, buscando repensar as relações que constituem a escola, principalmente suas hierarquias. 


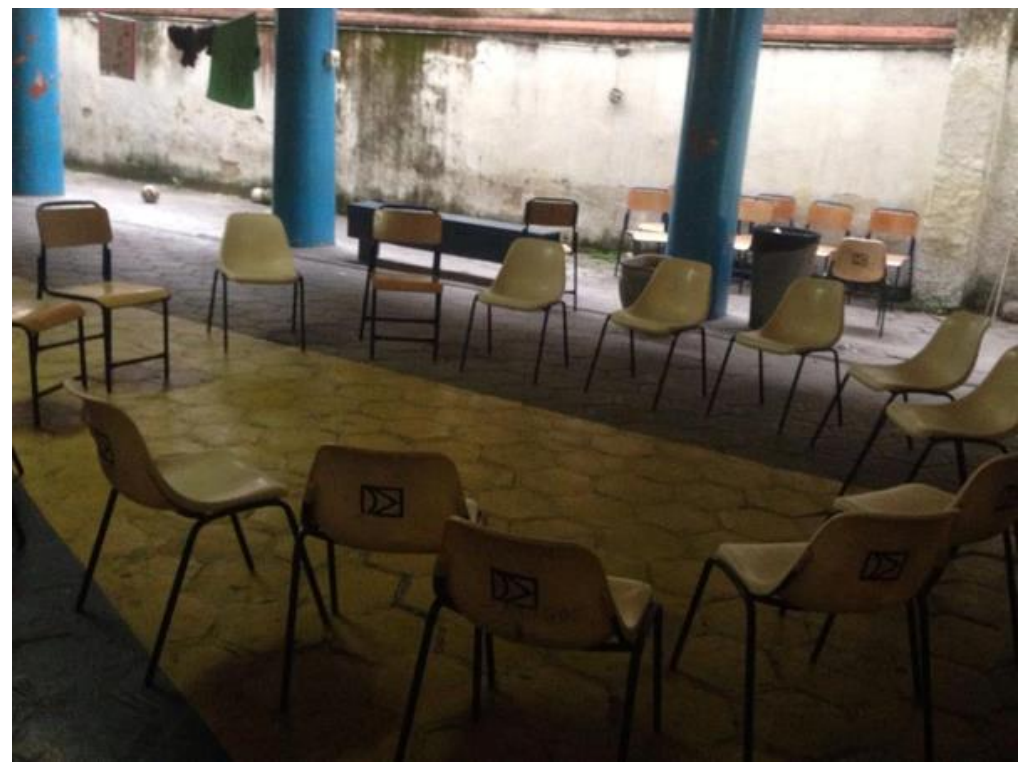

Convite ao diálogo, escola ocupada, RJ, 2016. Foto: D. Pinheiro.

Do ponto de vista do projeto de extensão, duas novas perspectivas abertas permitirão o desenvolvimento de novas pesquisas e ações em comum com as escolas. A primeira, refere-se a ao potencial que tem o convívio entre estudantes universitários e secundaristas, pois promoveram rodas de conversa onde o tema foi sempre a dificuldade que os jovens, especialmente os de origem popular, têm em conseguir manter-se no sistema educacional. Além dessa origem social comum, eles repartiam uma reflexão a respeito da fase turbulenta de sua trajetória representada pela passagem do Ensino Médio para o Ensino Superior. Segundo a opinião tanto dos estudantes secundaristas quanto dos universitários, essa transição é um pouco solitária, pois, muitas vezes, não encontram os suportes necessários para sua caminhada educacional nem na família, nem na escola. Por isso, este é um período de suas vidas marcado por muitas frustações. Atualmente, as pesquisas se concentram nas questões relativas a cada etapa de ensino, mas dedicam pouca atenção a esse período de passagem de níveis de ensino, que são essências na sua futura transição para a vida adulta.

A segunda questão diz respeito à militância política como forma de aprendizado. A validade do saber militante foi alvo de questionamentos permanentes ao longo da constituição das Ciências Sociais, devido à necessidade de isenção que legitima o saber científico. Somente a partir da obra de Florestan Fernandes, que a relação entre militância e reflexão acadêmica adquiriu uma maior consistência, pois Florestan conseguiu produzir uma obra profundamente política sem abandonar o rigor científico, 
promovendo uma abordagem crítica da realidade, ao mesmo tempo engajada e analítica, que não escamoteava o lugar de onde o autor se posicionava, mas nem por isso abria mão do rigor metodológico com as fontes (Fernandes, 1979). O tamanho da desigualdade brasileira, pensada em termos das oportunidades educacionais disponíveis à juventude, torna imensa a responsabilidade dos intelectuais brasileiros minimamente conscientes dessa distância social. Por isso, ouvir o que têm a dizer os jovens militantes que lutavam pelo materialização do direito à Educação tem uma grande importância nesse intenso debate intelectual, onde cada geração volta a se questionar: que país é este?

Por fim, vale destacar que a grande conquista das ocupações foi abrir um debate sobre a escola e sobre o sentido da Educação. Muitas direções de escola foram destituídas de suas funções e a eleição da nova direção pela comunidade escolar tem sido a regra, finalmente, adotada na maioria das escolas. Lamentavelmente, a Lei 13.415, de 16 de fevereiro de 2017, que reforma o Ensino Médio, foi promulgada sem uma consulta mínima à comunidade escolar: professores, gestores e estudante. Nesse sentido, a reforma já nasceu com pouca legitimidade. Suas propostas de flexibilização vão em direção oposta às demandas juvenis, que buscam novos sentidos para a Educação, mas não querem um currículo massificado ou aligeirado. Ao que tudo indica, as sementes críticas deixadas pelas ocupações vão geminar em pouco tempo, talvez mais rápido do que se pensa.

\section{Referências}

ANDRADE, E.; PINHEIRO, D.; ESTEVES, L.C.G (Org.). Juventude em Perspectiva: Múltiplos Enfoques. Rio de Janeiro: Editora UNIRIO, 2014.

BARRINGTON MOORE Jr. Injustiça: as Bases Sociais da Obediência e da Revolta. São Paulo: Editora Brasiliense, 1987.

CARVAlHO, J.M. Os Bestializados: o Rio de Janeiro e a República que Não Foi. São Paulo: Companhia das Letras, 1987.

ELIAS, N. Envolvimento e Alienação. Rio de Janeiro: Bertrand Brasil, 1998.

FREITAS, M.V. Jovens e escola: aproximações e distanciamentos. In: Novaes, R.; Venturi, G.; Ribeiro, E.; Pinheiro, D. (Org.). Agenda Juventude Brasil. Leituras sobre uma Década de Mudanças. Rio de Janeiro: Editora UNIRIO, 2016.

NOVAES, R. Os jovens de hoje: contextos, diferenças e trajetórias. In: ALMEIDA, M. I.M.; Eugênio, Fernanda (org.). Culturas Jovens: Novos Mapas do Afeto. Rio de Janeiro: Jorge Zahar, 2006.

OLIVEIRA, R.C. O Trabalho do Antropólogo. São Paulo: Edições Paralelo 15/Editora UNESP, 1998.

PINHEIRO, D.; ESTEVES, L.C.G.; FARAH NETO, M. Demandas dos jovens brasileiros. In: Fernandes, F. Mudanças Sociais no Brasil. Aspectos do Desenvolvimento da Sociedade Brasileira. São Paulo-Rio de Janeiro: Editora Difel, 1979. 
SITRIN, M. Horizontalism and occupy movements. In: Nova Iorque: Dissent Magazine, spring, 2012.

Recebido em: 30/05/2017. Aprovado em: 01/08/2017. 